\title{
Improved Embodied Energy and Carbon Accounting: Recommendations for Industry and Policy
}

\author{
By Efstratios Gavotsis ${ }^{*}$ \\ Alice Moncaster ${ }^{\dagger}$
}

\begin{abstract}
The majority of carbon emissions arise from the built environment, a fact which has led to a global policy focus on reducing carbon and energy from buildings in use. However, research demonstrates that embodied carbon is also an increasingly significant proportion of the whole life impacts from buildings. Embodied carbon is not yet the subject of regulation, and although the CEN TC350 standards provide a methodology, there remains a significant variation in its measurement. This paper investigates some of the issues and difficulties that need to be addressed before widescale regulation can be enforced. The investigation uses a detailed case study of a low-energy school building, studied during its construction phase. The cradle-to-grave embodied impacts were modeled to the TC350 Standards using an innovative tool, and the operational impacts were modeled to incorporate future climate predictions. In spite of the care taken over data collection and the collective support of the process from all stakeholders, the study demonstrates a high level of uncertainty in results, resulting from industry-wide barriers to embodied carbon measurement. Key recommendations are made for industry and policy, in order to overcome the current barriers and enable more accurate and comparable measurement of the embodied carbon of buildings.
\end{abstract}

\section{Introduction}

The built environment accounts for approximately $40 \%$ of the world's total energy consumption (United Nations, 2009) and the latest regulations (The European Parliament and The Council of the European Union, 2010) demand that buildings produce zero net operational $\mathrm{CO}_{2}$ emissions in the near future. Nevertheless, this strategy omits the embodied energy and embodied carbon (EE\&EC) which constitute a considerable amount of the building's total energy (E) and carbon (C) (2\%-46\%) with values up to $500 \mathrm{MJ} / \mathrm{m}^{2} /$ year (Ramesh et al., 2010; Sartori and Hestnes, 2007). This energy and carbon are emitted during the production of the building materials, the construction, the use and the end

${ }^{*}$ Engineer, Ramboll UK, UK.

${ }^{\dagger}$ Lecturer, University of Cambridge, UK. 
of the building life. The inclusion of those burdens is not currently a legislative requirement and only voluntary standards, such as the European CEN TC350 standards, "the basis of measuring embodied energy and carbon in products and projects" (HM Government, 2010), exist. The academic literature offers a number of studies of individual buildings using Lifecycle Assessment (LCA) (International Standards Organisation, 2006), but the inconsistencies and variations make comparison between them difficult (Dixit et al., 2010). It has been also demonstrated that the error in any typical embodied energy analysis may be as high as $20 \%$ (Langston and Langston, 2008) with a potential additional $50 \%$ error due to the incomplete boundaries of the process-based LCA method (Lenzen and Treloar, 2002). Although the process method is that used by the TC350 standards, it has been described as "extremely complex and time-consuming" compared to the alternative input-output method, or to the hybrid methods developed (Dixit et al., 2010). Nevertheless, the TC350 standards are being widely incorporated into calculation methods across Europe, and are likely to form the basis of any emerging legislation.

To understand the issues and barriers to calculating the embodied energy and carbon to the TC350 standards, a case study was developed of a new energy efficient school building under construction in Cambridge in the UK. Its operational energy consumption was also estimated using dynamic simulation software (Figure 2). There was collaboration and keen interest from all parts, leading -it would be assumed- to easily accessible data. The "Ecoclassroom" (Figure 1) integrates low-energy features and makes extensive use of local workforce, environmentally friendly materials and sustainable construction methods, while it has been designed to withstand 2080 conditions. A table showing the basic information for the building and its analysis is shown below.

Table 1. Identity of the Study and Basic Information for the EE\&C Calculation

\begin{tabular}{|c|c|}
\hline \multicolumn{2}{|c|}{ IDENTITY OF THE STUDY, Phase IIA, Ecoclassroom } \\
\hline & General data \\
\hline Country: & Cambridge, UK (suburban area) \\
\hline Fuel Mix: & Current \\
\hline Lifespan investigated: & Up to $2080-68$ years in total from the date of the study \\
\hline Type of energy: & Primary \\
\hline GEA/GIFA $\left(\mathrm{m}^{2}\right)$ : & 195/171 (excludes playground storage room) \\
\hline Volume $\left(\mathbf{m}^{3}\right)$ : & 550.63 \\
\hline Orientation: & East-West adjoining a 1960s building \\
\hline Window/Wall (\%): & 16.30 \\
\hline Skylight/Roof (\%): & 1.43 \\
\hline Use: & Education \\
\hline Rooms (single storey): & $\begin{array}{l}\text { Teaching area, wet room, quiet room and associated cloakroom, } \\
\text { toilets and disabled shower facilities }\end{array}$ \\
\hline \multicolumn{2}{|c|}{ Embodied Energy (EE) and Carbon (EC) study } \\
\hline Standards: & TC350 \\
\hline Method: & Process-Based, 'cradle to grave' \\
\hline Reporting Units: & Joules/kgCO $2(\mathrm{e})$ \\
\hline Data for $E \& C$ & \\
\hline coefficients: & Bath ICE v2.0 [21], EPDs, ECEB tool [16] \\
\hline Feedstock energy: & Included through the Bath ICE v2.0 \\
\hline
\end{tabular}


Figure 1. The West Façade of the Building Studied (Verve Architects)

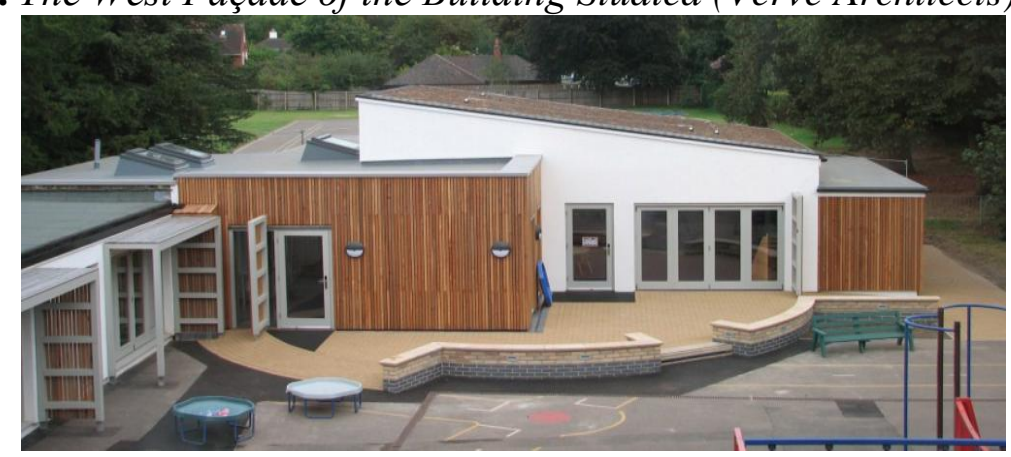

Figure 2. The Building Simulated in DesignBuilder

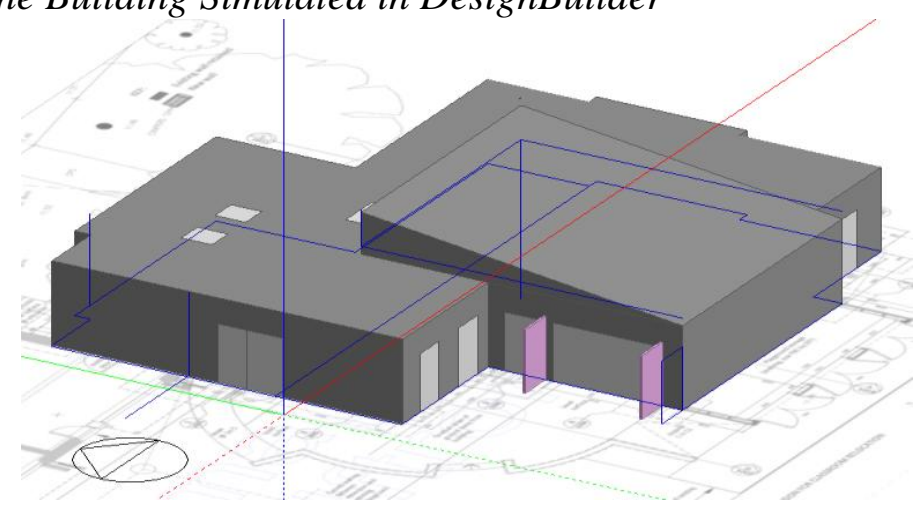

\section{Methodology and Results}

\section{Overview}

The research deployed various methods to answer the questions posed. In the centre lies the case study, supported by simulation, observation and interviews. The boundaries of the investigation are shown in the following table 2 and the equation for the whole life embodied carbon used takes the adapted form (Moncaster and Symons, 2013):

Equation 1

ECwholelife $=\sum^{n} E$ Cmat $($ comp $) i+\sum^{n} E$ Ctransp $($ comp $) i+E C$ constr $+\sum^{n} E$ Crefurb comp $) i+E C e n d l i f e-E C r e c o v e r$ where:

- (comp)i: is a particular component $i=1,2,3 \ldots n$

- EC: is the carbon emitted during the

○ EC mat: material production stage,

O EC transp: transport of materials to site,

- EC constr: processes involved in constructing the building,

- EC refurb: repair, refurbishment and replacement of components

○ EC endlife: processes involved in demolition and waste processing, and

- EC recover: is the carbon reclaimed due to certain future uses of the materials. 
The embodied energy terms are similar to those for carbon.

There were several known limitations to the method followed. The potential future decarbonisation of the UK national electricity grid was not accounted for. For materials and components where there was no information about the carbon equivalent $\left[\mathrm{CO}_{2}(\mathrm{e})\right]$, the $\mathrm{CO}_{2}$ data was used (Hammond G. P. and Jones C. I., 2008). The EE\&EC in the infrastructure, fuel processing, power plants and distribution systems were not included, nor was that of the water consumed during construction or operation.

The calculation was conducted using an in-house tool, developed at the Centre for Sustainable Development at Cambridge (Moncaster and Symons, 2013) for a number of reasons; the methods behind commercial software are not always clear and most tools do not conduct LCAs specifically for whole buildings. Those do tend to have a cradle-to-construction approach or are limited design-decision tools. Additionally, there is often an inability to consider the EE\&EC coefficients of components manufactured in other countries (Moncaster and Song, 2012).

In calculating operational energy, it was not possible to disaggregate the actual consumption after one year of use since the electricity supply was shared with another two buildings. The design team had already run simulations but they presented differences, and therefore additional simulations were run by the authors using DesignBuilder, and incorporating 2080 climate predictions ("Future weather files - University of Exeter," 2010).

Table 2. The Boundaries of the Investigation (Highlighted) [from BSEN15978:2011 (British Standards Institution: London, 2011)]

\begin{tabular}{|c|c|c|c|c|c|c|c|c|c|c|c|c|c|c|c|}
\hline \multicolumn{16}{|c|}{ Building Assessment Information } \\
\hline \multicolumn{15}{|c|}{ Building Life Cycle Information } & $\begin{array}{l}\text { Beyond } \\
\text { Building }\end{array}$ \\
\hline \multicolumn{3}{|c|}{ Product Stage } & \multicolumn{3}{|c|}{$\begin{array}{l}\text { Construction } \\
\text { Process Stage }\end{array}$} & \multicolumn{5}{|c|}{ Use Stage } & \multicolumn{4}{|c|}{ End of Life } & $\begin{array}{l}\text { Benefits } \\
\text { and } \\
\text { Loads }\end{array}$ \\
\hline A1 & A2 & A3 & A4 & & A5 & B1 & $\mathrm{B} 2$ & B3 & B4 & B5 & $\mathrm{C} 1$ & $\mathrm{C} 2$ & $\mathrm{C} 3$ & $\mathrm{C} 4$ & $\mathrm{D}$ \\
\hline \multirow{3}{*}{ 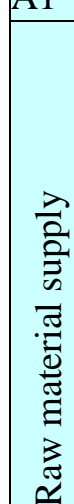 } & \multirow{3}{*}{ 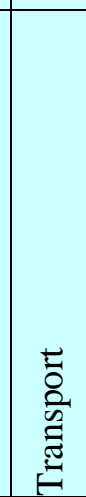 } & \multirow{3}{*}{\multicolumn{2}{|c|}{ 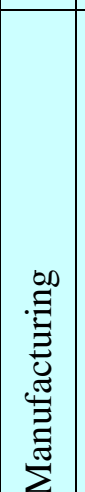 }} & & \multirow{3}{*}{ 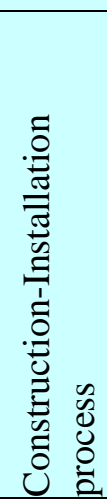 } & $\stackrel{0}{g}$ & . & 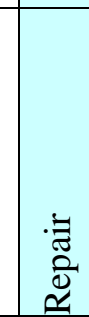 & 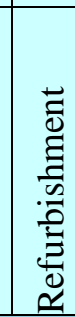 & 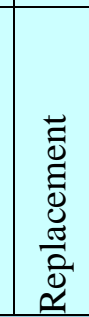 & \multirow{3}{*}{ 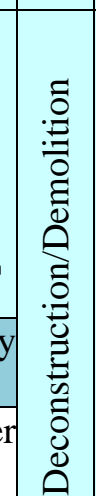 } & \multirow{3}{*}{ 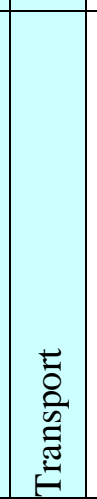 } & \multirow{3}{*}{\multicolumn{2}{|c|}{ 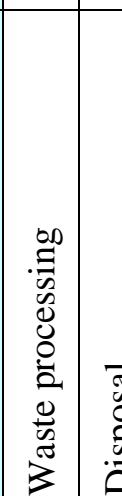 }} & \multirow{3}{*}{ 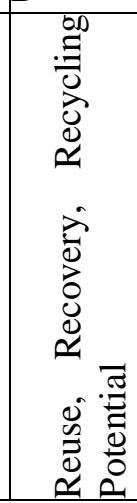 } \\
\hline & & & & & & B6 & $\begin{array}{l}\text { Op } \\
\text { use }\end{array}$ & ration & nal e & nergy & & & & & \\
\hline & & & & & & 37 & & eration & & water & & & & & \\
\hline
\end{tabular}




\section{Overall Results}

The calculation resulted in a total (whole life) primary energy use of 7239 GJ, equal to $622 \mathrm{MJ} / \mathrm{m}^{2} /$ year ( 68 years, $171 \mathrm{~m}^{2} \mathrm{GIFA}$ ). The lifespan of the building was assumed to be to 2080, since this was the year that climate data was available for. The respective value for carbon was estimated to rise to $39 \mathrm{kgCO}_{2}(\mathrm{e}) / \mathrm{m}^{2} /$ year. The ratio of embodied to operational energy (EE, OE) for the whole life of the building was approximately equal to $1: 2$ and the ratio for carbon was 1:1.5. The breakdown of the total carbon is shown in Figure 3 and Figure 4.

Figure 3. Total Lifecycle $\mathrm{CO}_{2}($ e) Breakdown (\%)

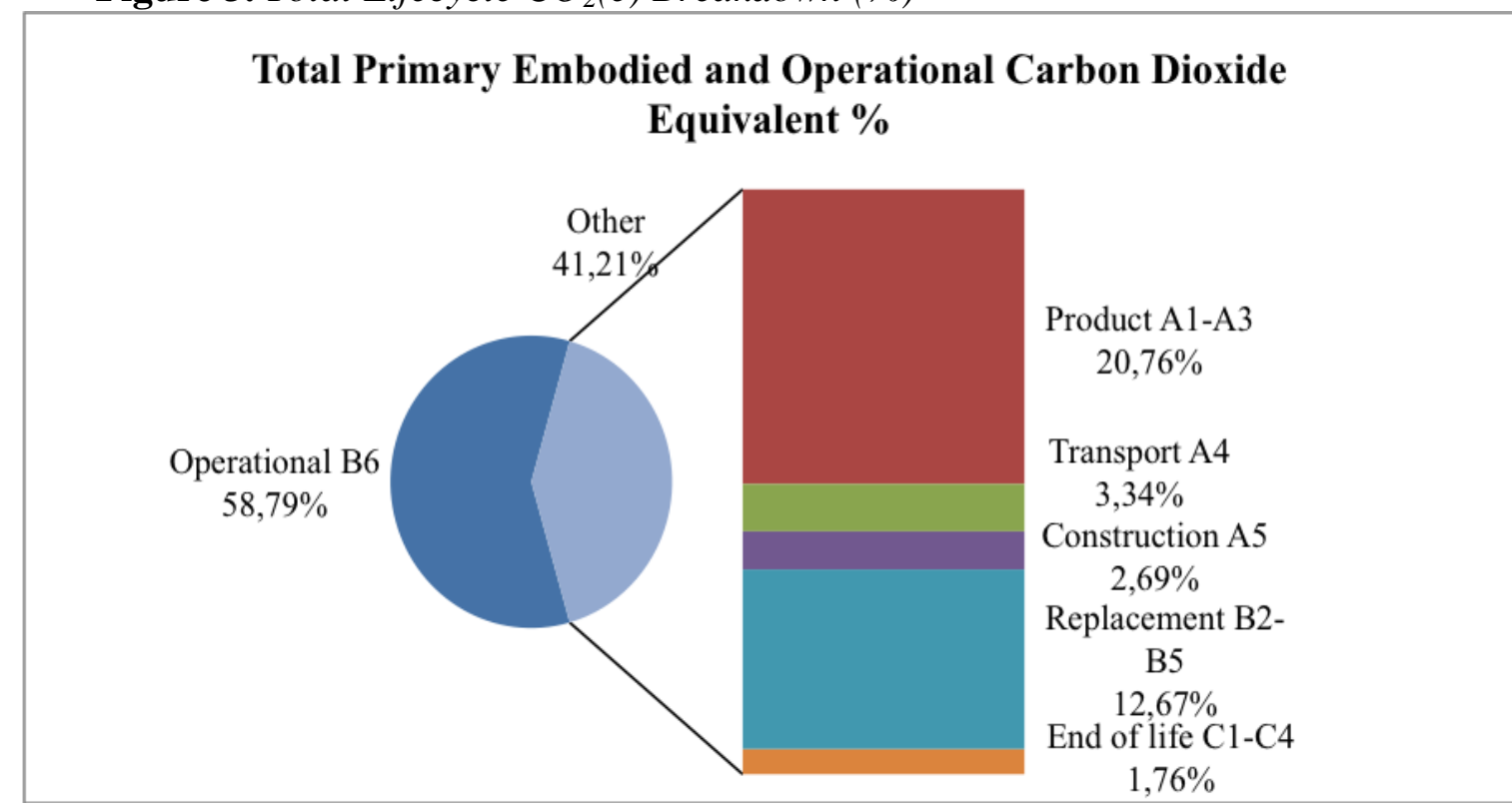

Figure 4. Total Lifecycle Carbon Dioxide Equivalent Breakdown $\left(\mathrm{tCO}_{2} e\right)$

\begin{tabular}{|c|c|c|c|c|c|c|}
\hline \multicolumn{7}{|c|}{$\begin{array}{c}\text { Total Primary Embodied and Operational Carbon Dioxide } \\
\text { Equivalent tCO2/m2 GIFA }\end{array}$} \\
\hline 2,00000 & \multicolumn{6}{|c|}{ Operational B6; } \\
\hline \multirow{5}{*}{$\begin{array}{l}1,00000 \\
0,50000 \\
0,00000\end{array}$} & \multicolumn{6}{|c|}{ Product A1-A3: } \\
\hline & \multirow{2}{*}{\multicolumn{2}{|c|}{0,55513}} & \multicolumn{4}{|c|}{$\begin{array}{c}\text { Replacement B2- } \\
\text { Transport A4;Construction A5; B5; 0,33875End of life C1-C4 }\end{array}$} \\
\hline & & & 0,08923 & 0,07185 & & 0,04702 \\
\hline & B6 & $\mathrm{A} 1-\mathrm{A} 3$ & A4 & A5 & B2-B5 & $\mathrm{C} 1-\mathrm{C} 4$ \\
\hline & Operational & Product & Transport & Construction & Replacement & End of life \\
\hline
\end{tabular}


The analysis showed that the absolute values for the whole lifecycle and embodied energy were in good proximity with the range reported by other studies for low energy buildings (Ramesh et al., 2010; Sartori and Hestnes, 2007).

The percentage for the A1-3 Stage is either similar or slightly higher than these reported by a number of different authors (Adalberth, 1997; Adalberth, K. et al., 2001; Cole and Kernan, 1996; Moncaster and Symons, 2013; Winther and Hestnes, 1999), and similarly for the absolute energy (Crawford, 2008; Hammond G. P. and Jones C. I., 2008; Nässén et al., 2007) and carbon values (Hacker et al., 2008; Hammond G. P. and Jones C. I., 2008; Royal Institution of Chartered Surveyors, 2012) of process-based studies. In this building, the timber and concrete were responsible for the highest shares of embodied energy and carbon, respectively.

For transport, the percentile value was lower or within the range reported by others. However, it is significantly higher than that of Monahan and Powell whose study concerned a similarly timber frame building. For carbon, the percentage is similar to that of Moncaster and Symons (Adalberth, 1997; Dixit et al., 2013; Monahan and Powell, 2011; Moncaster and Symons, 2013).

Tellingly, in spite of the fact that offsite construction is said to be a carbon efficient form of construction (Monahan and Powell, 2011; WRAP, 2008), the construction impact calculated in this study was significantly higher than that reported elsewhere in the literature (Adalberth, 1997; Cole and Kernan, 1996; Moncaster and Symons, 2013), although the percentile contributions to the lifecycle embodied energy were fairly close to other studies (Ding, 2005; Moncaster and Symons, 2013). This fact can be partly attributed to the small building scale. The on-site waste mass produced $\left(86.49 \mathrm{~kg} / \mathrm{m}^{2}\right.$ excluding inert materials) was close to values from similar studies [e.g. (Monahan and Powell, 2011)].

The absolute energy values and percentages for material replacement during the life of the building were either close or higher to the ones calculated by others. An exception to this is Thormark's study which has almost four times less (Cole and Kernan, 1996; Ding, 2005; Moncaster and Symons, 2013; Thormark, 2002). Concerning carbon, the percentage is lower or within the range of others (Hacker et al., 2008; Moncaster and Symons, 2013). This stage was calculated to produce waste equal to $16.7 \%$ of the initial mass of the building, with the highest impacts from the fixtures and fittings.

The end-of-life stage was assessed based on current demolition practices. It was found to give the smallest burden of all stages.

Allowing for timber sequestration could decrease the total carbon by between 5 and 9\% which was calculated based on a paper by Symons et al. (Symons et al., 2013). Finally, for operational energy, results were in close proximity to those of the building services engineers (differing by $8 \%$ ).

Impacts by Assembly

Little research refers to the contribution of the constituent parts of a building (Optis and Wild, 2010). This is due to the lack of a common approach 
on the issue but also because of the difficulty of assigning a product to one category only. Also, researchers tend to include or exclude parts, depending on the scope of their research, bringing variations to the results (Dodoo et al., 2012; Monahan and Powell, 2011)]. The simple approach followed here was that only the components attached to the building were included.

Figure 5. Impacts Broken Down by Assembly

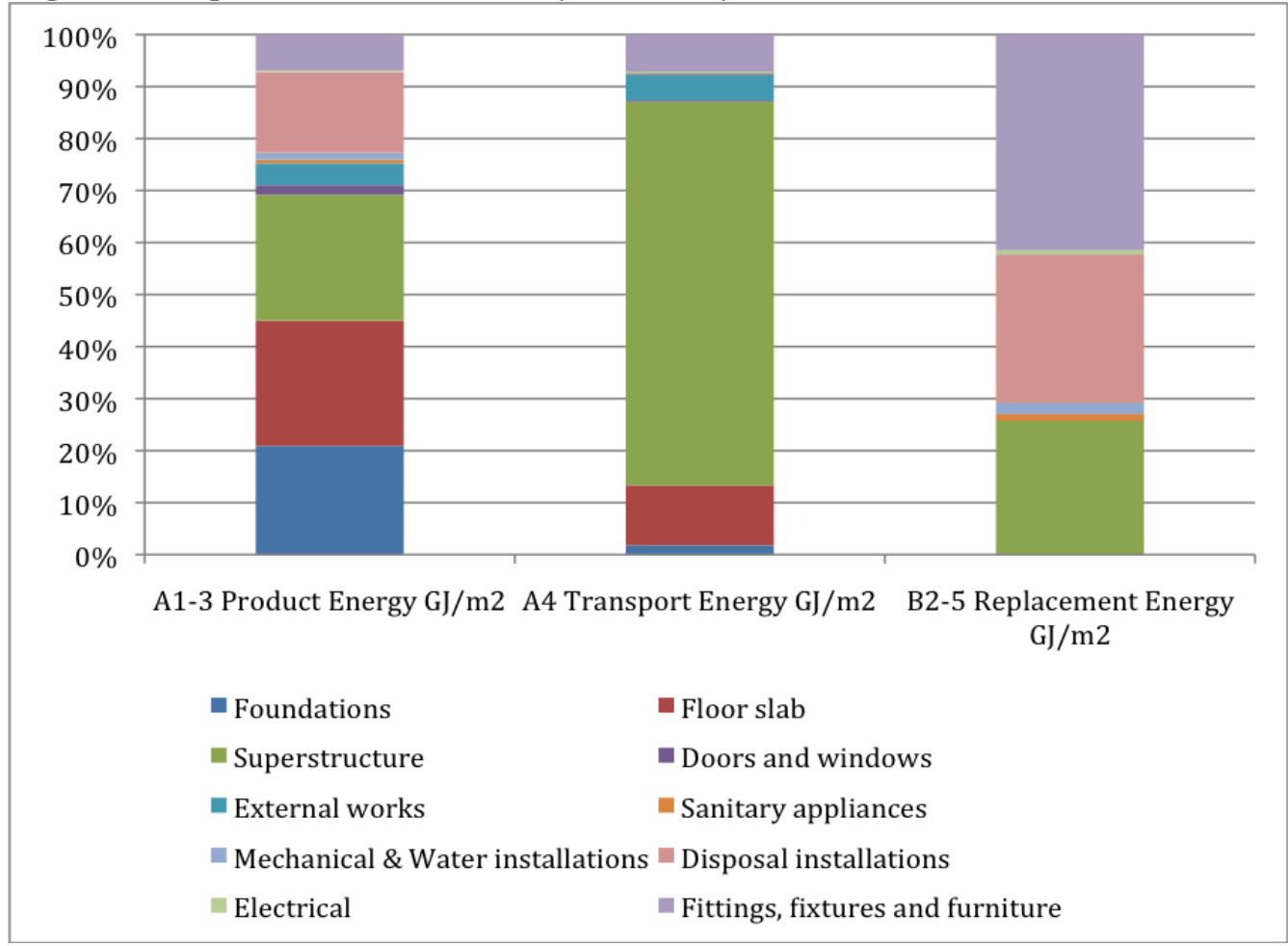

As illustrated in Figure 5, the greatest EE\&C impact, for the product stage, came from the superstructure (timber) and the floor slab (concrete). For the transport stage, over half of the total impact came from the superstructure. Regarding specific assemblies for the A1-4 stage, external works are not included in most of the studies (Hammond G. P. and Jones C. I., 2008) and the value calculated was much lower than the ones found in the literature [e.g. (Hammond G. P. and Jones C. I., 2008)]. This may be attributed to the fact that these works are site-specific (Dixit et al., 2013). Building services were the most difficult components to calculate. They had an impact of approximately $7 \%$ in the product stage. That was different from the range of 19\%-25\% reported elsewhere (Cole and Kernan, 1996; Ding, 2005). The differences noticed may be attributed to the lack of separate central heating installations. Finally, the only source found referring to fittings was Treloar et al. (Treloar et al., 1999) who found $1.5 \mathrm{GJ} / \mathrm{m}^{2}$, for the A1-3 stage using the input-output method $\left(0.77 \mathrm{GJ} / \mathrm{m}^{2}\right.$ in this study). This may be because of the different boundaries and assumptions used in their paper. The contribution of each assembly significantly changed in the replacement stage B3-5. The foundation and floor slab had no influence and the main burden was shifted to the fittings, 
the finishes and the paint. Building services increase to $9.5 \%$ for the B3-5 stage but this is considered low given that there is a need for replacement every 5-35 years (Cole and Kernan, 1996; Ding, 2005). Dixit et al. (Dixit et al., 2013) cite that this may be equal to 3.2 times the "initial" EE. Therefore, the embodied energy is likely to be much higher. As for the furniture, Treloar et al. (Treloar et al., 1999) calculates a further $8.4 \mathrm{GJ} / \mathrm{m}^{2}$ for stages B3-5, reaching an impressive $31 \%$ of the total whole life delivered energy of the building when the current study finds only $3.61 \mathrm{GJ} / \mathrm{m}^{2}$.

\section{Issues Faced during the Process}

In spite of the effort taken over the acquisition of high data quality, the case study demonstrates a high level of uncertainty for the calculation of embodied carbon and energy at each lifecycle stage as indicated by the comparisons above. The main reasons are outlined below.

\section{Lack of a Data Collection Method for Stages A1-A5}

Perhaps one of the most significant issues was the lack of standard method for the collection of data on the type, number and specification of components used in the building, or on their transport to site, the construction energy used, the waste produced and its destination (although the WRAP programme has gone a considerable way towards addressing this). The collection of data by the researchers was dependent on personal relationships and the time since completion of the project. The speed and quality of data collection was hampered by the fact that the main contractor had employed several different subcontractors for different packages, as is normal practice in the UK, which led to an estimated 10-30\% missing data for both EE \& EC.

For the product stage, the study followed a number of successive ways to gather accurate and complete data, including the collection of delivery tickets for materials arriving on site, use of design and construction issue drawings, contractor estimations, interviews with the contractors, correspondence with manufacturers and several site visits. Despite this effort, significantly more time consuming than a commercial embodied impact measurement process would allow for, a number of components were either: not identified at all; identified but out of scope; identified but not calculated because of their size or complexity; identified but not calculated due to the lack of information; or identified but only a rough estimate of impact made.

If the calculation had been based only on the Bill of Quantities list given to the authors by the contractor, without further research, it was calculated that the EE values for stages A1-3 and A4 would have been underestimated by $33 \%$ and $50 \%$. The respective underestimation for the replacement stage would have been $32 \%$ and these changes have impacts on the construction and demolition EE\&EC too through the calculation of waste materials. The total underestimation would have been $30 \%$ and $25 \%$ for EE and EC, respectively. The calculations were made using the same assumptions as the detailed study. 
In calculating the transport stage it was found that most components were either manufactured in the UK or imported from Europe. Some suppliers provided information concerning the means of transport and the route followed. The distance from the factories to the distribution centres and the final site was included using Google Maps. When information was not available for the means of transport, the most reasonable approach was followed. The transportation of the construction equipment to and from the site was also included through delivery tickets, although this was a very small amount.

Finally, the Construction module A5 was given by the following components:

Production and Transportation of Materials Lost or Damaged During Construction

There were different approaches on how to calculate the impact [e.g. (Blengini, 2009; Gustavsson et al., 2010)] since no data was available from the contractors. This is either because they had kept no records or because they were reluctant to sharing the information. Most researchers would increase initial quantities by a factor but, in this research, it was calculated as the fraction of the mass of waste to the total mass of initial materials, multiplied by the total E\&C contribution of the A1-4 stage (Equation 2).

Equation 2

EC prod \& transp of lost /dam $=\left(\frac{\text { totalmassof waste }}{\text { total massof initial material }}\right) \times\left(\sum_{i=1}^{n} E C \operatorname{mat}(\right.$ comp $) i+\sum_{i=1}^{n} E C$ transp $($ comp $\left.) i\right)$

\section{Construction Energy}

Energy was consumed mainly at three sources: the diesel consumed on site, the school electricity consumption and the manufacturers. For the first, a crude estimation was provided by the contractor. For the second, the school electricity consumption for the previous and the following year were compared with that of the construction year (2012), for the relevant periods. Only the timber-frame subcontractor was able to provide approximated data corresponding to the off-site construction.

\section{Waste}

The volume of the on-site construction waste was calculated but their exact composition and mass were unknown and therefore were calculated based on pro-rata values by two reports (British Research Establishment (BRE), 2012; Department for Environment, Food and Rural Affairs (DEFRA) et al., 2006). For the off-site waste, information was requested from the factories but -again- only the timber factory management was able to provide some information. Only the transport of the muck-away (uncontaminated soil) and the construction waste to the final site was included in the calculation. Neither the waste processing nor the disposal was included due to limited data. 


\section{Lack of Published Figures for Embodied Impacts of Components}

The actual environmental impacts could only be calculated for a limited number of components as there is not yet an established culture for the creation of Environmental Product Declarations (EPDs) in the UK. The calculation of the EE\&EC impacts of the components was conducted using inventories (Hammond G. P. and Jones C. I., 2008; Moncaster and Symons, 2013, p. 350) and a few EPDs (only 5 out of almost 200 products identified, some of which were produced in other countries). For some composite components, it was necessary to approximate the contribution of the constituent materials, when this was not available from the manufacturer. The transport factors used were taken from a tool (Moncaster and Symons, 2013) that uses UK and European values that have been adapted to include the empty return journey. When information on the method of transport was not available for short distances, the rigid heavy-goods vehicle was chosen to provide a good approximation. The means of transport for the construction equipment was assumed to be the "articulated Heavy Goods Vehicle".

\section{Uncertainties for Post-construction Stages}

The calculation of the use stage was based on approximations that might over- or under-estimate the contribution of an element. Based on predictions of the design team, no major refurbishments will be needed. If the life expectancy of the component was small, a replacement was assumed to be carried out. Replacement factors have been suggested [e.g (Thormark, 2002)] but, they refer to assemblies rather than components. Instead, the authors used a report by the NAHB (Economics group of NAHB, 2007), few available product specifications and design team estimates to calculate the component life expectancy. This report however, is intended for residential buildings and the replacement values might be underestimated for a classroom. The production and transportation was assumed to be similar to modules A1-4, while the construction energy was equated to the fraction of the energy and carbon impact of the specific component in the A1-3 stage to the total impact of stage A1-3, times the total construction energy A5 (Equation 3). The impact of excessive materials used during replacement was not included, as there was no relevant data.

The total mass of waste was equal to the replaced components and only transport impacts were included.

Equation 3

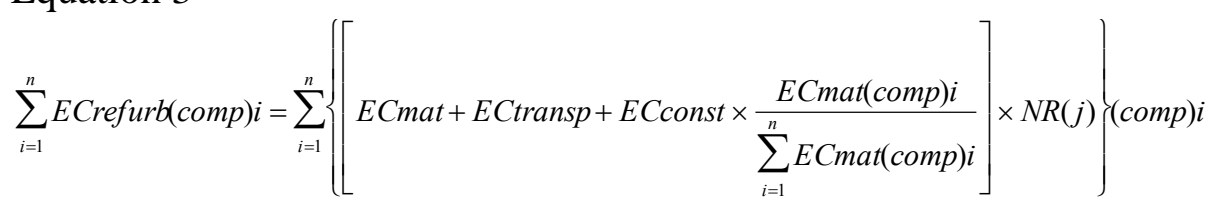

where $\mathrm{NR}(\mathrm{j})$ is the frequency of the material replacement.

Previous research concerning the demolition, the waste processing and the loads and benefits beyond the building lifecycle is limited (Monahan and Powell, 2011). For the End-of-life stage, the authors used the values of 
Moncaster and Symons (Moncaster and Symons, 2013) for the calculation of the deconstruction/demolition phase $(\mathrm{C} 1)$, as it is recent and UK-relevant. The demolition waste was assumed equal to the original mass of components and only its transport was included in the final impact.

Finally, a number of studies have been written on Carbon Sequestration (e.g. (Bateman and Lovett, 2000; Darby H. J., 2013; P Sadler and D Robson, 2012)). In this paper, it was commented separately and was not included in the final bill. The calculation only included the timber that was thrown to waste during the lifecycle of the building but none of its by-products. Since some building components were only $70 \%$ certified, a common approach of $70 \%$ sustainable timber was followed. The calculation was based on a paper by Symons et al. (Symons KE et al., 2013). The total burden or benefit depends on the final destination of this timber. It was assumed that $33.3 \%$ was sent to Landfill and therefore a total carbon burden from sequestration of $0.35 \mathrm{kgCO}_{2} / \mathrm{kg}$ and that the rest $66.6 \%$, was reused/recycled with a benefit of $1.80 \mathrm{kgCO}_{2} / \mathrm{kg}$ timber. The mass waste at the timber-frame factory was all recycled.

\section{Varied Boundaries, Multiple Calculation Methods}

Existing standards present differences in the method they follow, the boundaries, and the contribution and responsibility of each industry sector (Moncaster and Song, 2012). Had this study been based on stages A1-3 only, as advised by some standards and the government [e.g. (British Standards Institution: London, 2011; HM Government, 2010)], the embodied impacts would have been underestimated by approximately 50\%. Also, TC350 standards have inherent weaknesses [e.g. process-based method, omission of the impacts of the designer's offices, infrastructure, etc. (Treloar et al., 2001)] that should be considered.

\section{Limited Knowledge Dissemination}

The strategic decisions of clients, designers and contractors affect not only the current but also the future EE\&EC of a building. Despite the fact that the shareholders of this project were all informed on the importance of EE\&EC, most of the industry is not and their understanding is mostly based on the initial stages (A1-3) and common perception.

\section{Conclusion and Discussion}

At least a third of the total life building emissions are likely to come from the embodied energy and embodied carbon (EE\&EC) based on this study and others. Current policies do not regulate for these calculations. In order to be able to reach the targets set for carbon reduction, the construction industry needs to realise the importance of embodied carbon and take steps to measure and reduce it. As well as focusing on developing software, it should focus on 
creating data collection systems, EPDs, clear standards and precise methods, informing the industry and the society, giving incentives and setting targets.

Five important difficulties were faced in the process of calculating the EE\&EC of this classroom. A common approach is missing in terms of the assemblies and components included in the calculation (Cole and Kernan, 1996). It needs to be clear which of those will be used in calculations across the UK to allow direct comparison amongst studies conducted using the same standards. Existing databases should be enriched and updated to include more materials and composite components should be made publicly available and protected from industry interests, and as soon as possible these should be merged to form a Government-funded UK National database, similar to the Ökobau in Germany. EPDs should be obligatory for all manufactured products and include all lifecycle stages. Additionally, it is vital to create a digital database for the collection of post-construction information on EE\&EC that will give each building an "Identification" label, enabling access in the future. Finally, there should be an agreement on the standard, the boundaries and the method used for the calculation of EE\&EC and similar measures to those taken to decrease operational energy and carbon should be launched. The financial and social impacts of these actions should also be assessed.

With the development of EU and global standards defining the methodology for measuring EE\&EC, and increasing evidence that it is a significant proportion of the whole life impacts for a building, now is the right time for the calculation of cradle-to-grave/cradle EE\&EC impacts to be legislated, followed by increasing reduction requirements. There are many ways in which this could be done, for example by creating a system similar to the one used by SAP and SBEM in which a "standard" building is used as a comparison. Another way forward would be to agree on a target value, depending on the type of the building. Regulation would ensure pressure was put on the construction industry to accelerate its carbon reduction.

\section{Acknowledgments}

We would like to thank the stakeholders of the school: the architect Ms Daniela Muscat, the bursar of the school Mr Richard Brent, the contractor $\mathrm{Mr}$ Gareth Godfrey, the building services engineer Ms Sarah Leggo, and New World Timber Frame. We are grateful to the George and Marie Vergottis Foundation for financial support of Gavotsis during the period of this research at the University of Cambridge.

\section{References}

Adalberth, K., 1997. Energy use during the life cycle of single-unit dwellings: examples. Building and environment 32, 321-329. doi:10.1016/S03601323(96)00069-8

Adalberth, K., Almgren, A, Holleris Petersen, E., 2001. Life-cycle assessment of four multi-family buildings. International Journal of Low Energy and Sustainable 
Buildings 2, 1-21. doi:http://vbn.aau.dk/en/publications/lifecycle-assessment-offour-multifamily-buildings(573c51a0-165e-11dc-a5a4-

000ea68e967b)/export.html

Bateman, I., Lovett, A., 2000. Estimating and valuing the carbon sequestered in softwood and hardwood trees, timber products and forest soils in Wales. Journal of Environmental Management 60, 301-323. doi:10.1006/jema.2000.0388

Blengini, G.A., 2009. Life cycle of buildings, demolition and recycling potential: A case study in Turin, Italy. Building and Environment 44, 319-330. doi:10.1016/j.buildenv.2008.03.007

British Research Establishment (BRE), 2012. SmartWaste Plan-BRE waste benchmark data.

British Standards Institution: London, 2011. British Standards Institution, BS EN 15978, Sustainability of Construction Works-Assessment of environmental Performance of Buildings-Calculation Method. BSI.

Cole, R.J., Kernan, P.C., 1996. Life-cycle energy use in office buildings. Building and Environment 31, 307 - 317. doi:http://dx.doi.org/10.1016/0360-1323(96)00017-0

Crawford, R.H., 2008. Validation of a hybrid life-cycle inventory analysis method. Journal of Environmental Management 88, 496-506. doi:10.1016/j.jenvman. 2007.03.024

Darby H. J., 2013. A case study to investigate the Life Cycle Carbon Emissions and Carbon Storage Capacity of a Cross Laminated Timber, Multi-Storey Residential Building, in: SB13 Implementing Sustainability - Barriers and Chances. Presented at the Sustainable Building, Munich, Germany.

Department for Environment, Food and Rural Affairs (DEFRA), AEA Technology, British Research Establishment (BRE), 2006. Developing a strategic approach to construction waste. 20 year strategy draft for comment.

Ding, G.K.C., 2005. Developing a multicriteria approach for the measurement of sustainable performance. Building Research \& Information 33, 3-16. doi:10.1080/0961321042000322618

Dixit, M.K., Culp, C.H., Fernández-Solís, J.L., 2013. System boundary for embodied energy in buildings: A conceptual model for definition. Renewable and Sustainable Energy Reviews 21, 153-164. doi:10.1016/j.rser.2012.12.037

Dixit, M.K., Fernández-Solís, J.L., Lavy, S., Culp, C.H., 2010. Identification of parameters for embodied energy measurement: A literature review. Energy and Buildings 42, 1238-1247. doi:10.1016/j.enbuild.2010.02.016

Dodoo, A., Gustavsson, L., Sathre, R., 2012. Effect of thermal mass on life cycle primary energy balances of a concrete- and a wood-frame building. Applied Energy 92, 462-472. doi:10.1016/j.apenergy.2011.11.017

Economics group of NAHB, 2007. Study of life expectancy of home components. National Association of Home builders/Bank of America Home Equity.

Future weather files - University of Exeter [WWW Document], 2010. URL http://em ps.exeter.ac.uk/research/energy-environment/cee/projects/prometheus/termsand conditions/futureweatherfiles/ (accessed 6.17.13).

Gustavsson, L., Joelsson, A., Sathre, R., 2010. Life cycle primary energy use and carbon emission of an eight-storey wood-framed apartment building. Energy and Buildings 42, 230-242. doi:10.1016/j.enbuild.2009.08.018

Hacker, J.N., De Saulles, T.P., Minson, A.J., Holmes, M.J., 2008. Embodied and operational carbon dioxide emissions from housing: A case study on the effects of thermal mass and climate change. Energy and Buildings 40, 375-384. doi:10.1016/j.enbuild.2007.03.005 
Vol. 2, No. $1 \quad$ Gavotsis et al.: Improved Embodied Energy and Carbon Accounting...

Hammond G. P., Jones C. I., 2008. Embodied energy and carbon in construction materials. Proceedings of the ICE - Energy 161, 87-98. doi:10.1680/ener.2008. 161.2 .87

HM Government, 2010. Low carbon construction innovation and growth team-Final report.

International Standards Organisation, 2006. Environmental Management - Life Cycle Assessment - Principles and Framework, ISO 14040:2006.

Langston, Y.L., Langston, C.A., 2008. Reliability of building embodied energy modelling: an analysis of 30 Melbourne case studies. Construction Management and Economics 26, 147-160. doi:10.1080/01446190701716564

Lenzen, M., Treloar, G., 2002. Embodied energy in buildings: wood versus concretereply to Börjesson and Gustavsson. Energy Policy 30, 249-255. doi:10.1016/S0301-4215(01)00142-2

Monahan, J., Powell, J.C., 2011. An embodied carbon and energy analysis of modern methods of construction in housing: A case study using a lifecycle assessment framework. Energy and Buildings 43, 179-188. doi:10.1016/j.enbuild.2010. 09.005

Moncaster, A.M., Song, J.-Y., 2012. A comparative review of existing data and methodologies for calculating embodied energy and carbon of buildings. International Journal of Sustainable Building Technology and Urban Development 3, 26-36. doi:10.1080/2093761X.2012.673915

Moncaster, A.M., Symons, K.E., 2013. A method and tool for "cradle to grave" embodied carbon and energy impacts of UK buildings in compliance with the new TC350 standards. Energy and Buildings 66, 514-523. doi:10.1016/ j.enbuild.2013.07.046

Nässén, J., Holmberg, J., Wadeskog, A., Nyman, M., 2007. Direct and indirect energy use and carbon emissions in the production phase of buildings: An input-output analysis. Energy 32, 1593-1602. doi:10.1016/j.energy.2007.01.002

Optis, M., Wild, P., 2010. Inadequate documentation in published life cycle energy reports on buildings. The International Journal of Life Cycle Assessment 15, 644 651. doi:10.1007/s11367-010-0203-4

P Sadler, D Robson, 2012. Carbon sequestration by timber buildings. ASBP report.

Ramesh, T., Prakash, R., Shukla, K.K., 2010. Life cycle energy analysis of buildings: An overview. Energy and Buildings 42, 1592-1600. doi:10.1016/ j.enbuild.2010.05.007

Royal Institution of Chartered Surveyors, 2012. Methodology to calculate embodied carbon of materials: RICS information paper. Royal Institution of Chartered Surveyors, Coventry.

Sartori, I., Hestnes, A.G., 2007. Energy use in the life cycle of conventional and lowenergy buildings: A review article. Energy and Buildings 39, 249-257. doi:10.1016/j.enbuild.2006.07.001

Symons KE, Moncaster AM, Symons D, 2013. An application of the CEN TC350 standards to an Energy and carbon LCA of timber used in construction, and the effect of end-of-life scenarios. Presented at the Australian Life Cycle Assessment Society (ALCAS), Sydney, Australia.

The European Parliament, The Council of the European Union, 2010. Directive 2010/31/EU of the European Parliament and of the Council of 19 May 2010 on the energy performance of buildings (recast), L153/13.

Thormark, C., 2002. A low energy building in a life cycle-its embodied energy, energy need for operation and recycling potential. Building and Environment 37, 429-435. doi:10.1016/S0360-1323(01)00033-6 
Treloar, G.J., Love, P.E., Faniran, O.O., 2001. Improving the reliability of embodied energy methods for project life-cycle decision making. Logistics Information Management 14, 303-318. doi:10.1108/EUM0000000006243

Treloar, G.J., McCoubrie, A., Love, P.E.D., Iyer-Raniga, U., 1999. Embodied energy analysis of fixtures, fittings and furniture in office buildings. Facilities 17, 403410. doi:10.1108/02632779910291877

United Nations, 2009. United Nations Environment Programme (UNEP) - Buildings and Climate Change, Summary for Decision Makers [WWW Document]. URL http://www.unep.org/sbci/pdfs/SBCI-BCCSummary.pdf (accessed 5.6.13).

Winther, B.N., Hestnes, A.G., 1999. Solar versus green: the analysis of a Norwegian row house. Solar Energy 66, 387-393. doi:10.1016/S0038-092X(99)00037-7

WRAP, 2008. Waste Minimisation through Offsite Timber Frame Construction, Waste Resources and Action Programme. 
